\title{
Determinants of Farmers' Confidence Level in the Financial Sector of Ghana: A Case of the Ejura Sekeredumase Municipality of the Ashanti Region
}

\author{
Yenibehit Nanii ${ }^{1,2, *}$, Awoyemi Abiodun Emmanuel², Akorsikumah Eli Andreaws², \\ Akurugu Sumaila ${ }^{2,3}$, Adongo Azure Simon ${ }^{2}$, Adam Umar ${ }^{2}$, Alhassan Abdul Fataw ${ }^{2}$ \\ ${ }^{1}$ Department of Agribusiness, Animal Health and Production College, Pong Tamale, Ministry of Food and Agriculture (MoFA), Pong- \\ Tamale, Ghana \\ ${ }^{2}$ Department of Agricultural and Resource Economics, University for Development Studies (UDS), Nyankpala Campus, Nyankpala, Ghana \\ ${ }^{3}$ Department of Social Welfare and Community Development, Tolon District Assembly, Tolon - Northern Region, Ghana
}

Email address:

yenibehitnanii@gmail.com (Y. Nanii)

${ }^{*}$ Corresponding author

\section{To cite this article:}

Yenibehit Nanii, Awoyemi Abiodun Emmanuel, Akorsikumah Eli Andreaws, Akurugu Sumaila, Adongo Azure Simon, Adam Umar, Alhassan Abdul Fataw. Determinants of Farmers' Confidence Level in the Financial Sector of Ghana: A Case of the Ejura Sekeredumase Municipality of the Ashanti Region. International Journal of Agricultural Economics. Vol. 5, No. 3, 2020, pp. 71-79. doi: 10.11648/j.ijae.20200503.13

Received: May 2, 2020; Accepted: May 26, 2020; Published: June 17, 2020

\begin{abstract}
This paper adopted the PPO model to examine determinants of the confidence level of farmers on the financial institutions using 274 randomly selected farmers from Ejura Sekeredumase Municipality. About $44.9 \%$ of the farmers reported not having confidence in the financial institutions of the country, $21.9 \%$ were somehow confident in the sector, $17.5 \%$ were confident whereas only $15.7 \%$ were very confident in the sector. Male farmers were more likely to be very confident in the financial sector whilst education in years, farmers who ever lost savings or investment as well as those with current savings and/or investment all had positive outcome in the likelihood of being very confident in the financial sector. Duration of farmers with a financial institution and farmers who ever encountered challenges in a financial institution are less likely to be very confident in financial institutions in Ghana. The Central Bank should develop a different proactive educational model or approach to educate farmers on how to identify risk and other exposures that may be associated with the financial institutions operating in the rural areas in order to enable them to take decisions towards savings and investment. This will boost their confidence levels.
\end{abstract}

Keywords: Ejura Sekeredumase Municipality, Farmers, Financial Institutions, Parallel Lines Assumptions, Partial Proportional Odds Model

\section{Introduction}

The contribution of agriculture to the economic development of developing economies such as those of Africa cannot be underestimated. Economic growth and development of a country is a function of how healthy the agricultural sector is [1].

Ghana continues to depend largely on agriculture to fuel its economic growth and development despite the discovery and exploitation of oil in commercial quantities. Agricultural output grew tremendously between 2017 and 2018 largely due to government policy intervention and expenditure in the sector. However, in spite of its increased growth of $6.1 \%$ in 2017, the sector only saw $4.8 \%$ growth rate in 2018 with its overall contribution to Ghana's GDP dropping from $21.1 \%$ in 2017 to $19.7 \%$ in 2018 [2]. It is opined that despite the contribution of agricultural sector to the economic development of most developing countries, it is still the most vulnerable sector of any economy and receives the least budgetary allocations [3].

The positive outlook of agricultural contribution to Ghana's GDP can be attributed to the crops sub-sector, which continue to dominate the overall contribution to agricultural GDP of the country [4]. This sub-sector has the largest in 
agricultural GDP share of the economy, holding an activity of about $14.5 \%$ share of GDP in 2018 [2]. Crops, especially cereals form the most dominant crop subsector of the agricultural system in Ghana and provide a central pillar of the rural economy. Although crop production specifically cereals has seen an annual average growth rate of $6.51 \%$ from 1968 to 2017[2], the rising demand for these crops and the country's quest to drive the economy away from taxation to industrialization implies that the promotion of growth of crops and their value chains cannot be undermined.

Financial sector could be described as the "mitochondria" of any economy. In fact, the financial sector of every country serves as the engine of the country's economic growth and development. It provides the means of all activities of the various sectors of the economy. The sector is made up of financial institutions that provide liquidity for other economic players to undertake their economic activities. Therefore, the most valuable requirement and for that matter a vital input is the availability and accessibility of agricultural finance to peasant farmers who form the majority of the agricultural workforce of the country. It is believed that agricultural finance has the greatest potential of addressing food security, poverty reduction, and the need to preserve natural resources hence high investment in agricultural production in developing countries needs to be emphasized [5]. Financial institutions in Ghana offer the main sources of finance in the agricultural sector but the recent happenings and sudden closure of most financial institutions in Ghana raises doubts as to whether farmers have confidence and trust in the financial institutions of the country.

By convention, organisations including commercial banks, trust companies, lenders, rural banks, microfinance companies, insurance companies and investment dealers are classified as financial institutions that provide financial services to all players of the economy [6] and customer confidence and trust remains paramount to their operations.

The Bank of Ghana implemented the financial sector reforms with the aim of boosting customers and investors' confidence in the financial sector of the country. This is touted as yielding dividends as Key Financial Soundness Indicators (FSIs) are said to have improved in response to the reforms [7]. The Bank of Ghana also reported that the financial sector is well - capitalized, solvent, liquid and with high profits and better financial sector indicators [7]. However, in the light of these achievements, nothing has been said empirically about the confidence level of the investors and customers for which reason the reforms were undertaken.

In fact, the issue of confidence and trust of key individual decision-making units such as farmers who deposit, invest and /or obtain credit from these financial service providers to finance their farming activities is unknown. Since the collapsed, merger or the entire restructuring of the financial sector to boost investors and customers' confidence, no study has been conducted to examine the level of confidence farmers repose on the various financial institutions of the country. Although authors such as $[8,9,10]$, studied the financial sector in one way or the other, only Bola [11] studied public confidence in microfinance services in Ghana and this was even conducted before most of the reforms and collapsed of some financial institutions in the country. This study therefore aims at examining the confidence level of farmers on the financial institutions of the Ejura Sekeredumase Municipality of Ghana.

\section{Literature Review}

Confidence in financial institutions can be viewed as a very important factor that can ensure that financial institutions have a successful operations and development while making provision for continuous and higher consumer and banking cooperation [12]. The sector in Ghana however, for the past 5-6 years have been characterized as volatile and constantly loosing consumers' confidence.

Rich literatures on confidence in the financial sector especially in banks exist. For example in the study of the Dutch Banking Association [13] through their bank confidence monitor in 2017 , about $18 \%$ of customers were having high confidence in banks, $57 \%$ had neither high nor low confidence in the sector, while $25 \%$ had confidence. In their study, young people between the ages of 18 and 34 had the highest confidence with women having relatively higher confidence than men [13]. In comparing the confidence level of customers in Islamic banks and conventional banks, Hussein [14] reported that in general, customers had higher confidence in Islamic banks than conventional banks because they were more capitalized

Mosch and Prast [15] studied confidence and trust in Netherlands financial institutions and found out that consumers' confidence in Netherlands' financial institutions lowered sharply than other countries between $2000-2005$. Drobot (16), used co-integration analysis to analyse consumer confidence and household deposits and indicated that consumer confidence and household deposits were sharing a long - run equilibrium and that there was negative relationship between consumer confidence and household deposits.

In the financial sector of Ghana, Bola [11] studied public confidence in the microfinance companies and reported that there was no difference in the confidence index of men and women. Bola found a positive relationship between the level of confidence of the public on microfinance companies and the microfinance services they demanded. Customer satisfaction and respondent's level of education were determinants that affected how much confidence the person has in the microfinance institutions of the country.

\section{Study Area and Methodology}

\subsection{Study Area}

The study was conducted in Ejura Sekeredumase Municipality in the Ashanti Region. The municipal is bordered by Atebubu-Amantin Municipal to the northwest, Mampong Municipality to the east, Sekyere South District to the south and the Offinso Municipality to the west. The 
municipality covers a total land area of 1,340.1 square kilometres $[17 ; 18]$. It can be found within Longitudes $1^{\circ} 5^{\prime \prime} \mathrm{W}$ and $1^{\circ} 39^{\prime \prime} \mathrm{W}$ and Latitudes $7^{\circ} 9^{\prime \prime} \mathrm{N}$ and $7^{\circ} 36^{\prime \prime} \mathrm{N}$ and is a habitat to about 85,446 people according to the 2010 Population and Housing Census [18].

Agriculture is a dominant economic activity of the people and employs about $69.7 \%$ of the workforce in the municipality [17]. Approximately $80 \%$ of the total land in the municipality is arable and support crop production. As a result, about $97.4 \%$ of agricultural households in the municipality are engaged in crop production [18]. By virtue of its location within the forest/savanna transitional zone, both forest and savanna adapted crops especially maize, yams, cassava plantain groundnuts, rice etc. are cultivated in the municipality [18]. Maize, Groundnut and cowpea are produced on commercial scale in the municipality [17] and farmers may need capital from financial institutions of the area to fund their farming activities. Some financial service providers and banks provide capital resource and other financial related services to the farmers, businesses and people in the area.

\subsection{Sampling, Description of Variables and Data Collection}

A sample size of 274 randomly selected farmers were drawn from six communities in the municipality. The respondents were selected from Ejura, Sekyedumase, Anyinasuand, Kasei, Bouyaase and Miminaso. Data was gathered mainly from demographic variables finance related issues and the level of confidence farmers have in financial institutions in the municipality. Farm and production related data were collected to provide a fair idea on the nature of farming in the area but these variables did not enter into the analysis for this paper.

The data was collected using a well-structured open and closed ended questionnaire administered through personal interviews. The questionnaire was coded into Open Data Kit (ODK) build and extracted into Extensible Markup Language (XML) file format for administration in (ODK) collect, an android application for mobile phone data collection. Table 1 gives a summary description of the variables captured and used in the study.

Table 1. Variables' description

\begin{tabular}{lll}
\hline Variables & Description & Measurement \\
\hline Sex & Sex of respondents & Dummy: \\
EduY & Years of Education & Male $=1$, Female $=0$ \\
Farm Income & Farm income obtained in the last production season & Years \\
$\begin{array}{l}\text { Duration } \\
\text { Loan Access }\end{array}$ & Duration as committed customer to your financial institution in months & Months \\
Loan Amount & If a farmer accessed loan for crop production in the past 12 months. & Dummy: Yes $=1$, No $=0$ \\
ENChallenge & Have you ever encounter any challenge during a financial transaction with & Ghana cedi \\
LosInvestment & your financial institution & Dummy: Yes $=1$, No $=0$ \\
CINStautus & Current savings $/$ investment Status of respondents & Dummy: Yes $=1$, No $=0$ \\
Level & Level of confidence respondents' have in financial institutions of the country & Categorical: Very Confident $=1$, Confident $=2$, \\
\end{tabular}

Source: Field Survey, 2019.

\subsection{Theoretical Framework of the Partial Proportional Odds (PPO) Model}

This paper uses the partial proportional odds (PPO) to examine the confidence level of farmers on the financial institutions of Ghana after the major shakeups in the banking sector. The ordinal dependent variable was categorized into four i.e. Very Confident $(\mathrm{Y}=1)$, Confident $(\mathrm{Y}=2)$, Somehow Confident $(\mathrm{Y}=3)$ and No Confidence $(\mathrm{Y}=4)$. This type of dependent variable is best fitted with the generalized ordered logit (gologit) model. The model can be written as

$$
P\left(Y_{i}>j\right)=g\left(X \beta_{j}\right)=\frac{\exp \left(\alpha_{j}+X_{i} \beta_{j}\right)}{1+\left\{\exp \left(\alpha_{j}+X_{i} \beta_{j}\right)\right\}}, \mathrm{j}=1,2, \ldots \mathrm{M}-1
$$

Where $M$ represents the number of categories of the ordinal dependent variable. The probabilities that $Y$ is an outcome of a particular $M$ is given as follows according to Williams [19].

$$
P\left(Y_{i}=1\right)=1-g\left(X_{i} \beta_{1}\right)
$$

$$
\begin{aligned}
P\left(Y_{i}=j\right)= & g\left(X_{i} \beta_{j-1}\right)-g\left(X_{i} \beta_{j}\right), \mathrm{j}=2 \ldots \ldots \ldots \mathrm{M}-1 \\
& P\left(Y_{i}=M\right)=g\left(X_{i} \beta_{M-1}\right)
\end{aligned}
$$

The 4-outcome dependent variable $\mathrm{Y}$ represents an underlying discrete continuous latent variable, $\mathrm{Y}^{*}$ which assumes a linear combination of some explanatory variables and an error term denoted structurally as $Y *=X \beta+\varepsilon$. In this study, let $\mathrm{Y}^{*}$ be the unobserved attitude of the farmers towards the financial institutions of the country which is expressed by how confident they are in the financial sector. For the fact that the outcome categories of the variable is ordered in order of how confident the respondents are in the financial sector of the country, the standard ordered logit model is the appropriate approach to use.

A formal test, after the standard ordered logit model revealed that the final model violated the parallel lines assumption thereby making it inappropriate as hinted by Bender and Grouven [20]. This paper therefore adopted the partial proportional odds model that allows some variables to violate the proportional odds assumptions. 
According to Williams [19], there are three cases of the ordered logit model as far as relaxing or imposing the proportional odd assumption is concern. These are:

The proportional odds case (standard ordered logit) which is most restrictive but most parsimonious. This model holds the assumption that each of the m outcomes meet the parallel line assumption and therefore has equal vector of coefficients, $\beta s$ across all $m$ outcome categories.

The second case is referred to as the partial proportional odds case (the model this paper has adopted, fitted by gologit2) which relaxes the parallel lines assumption for some of the coefficients, $\beta s$ across $m$ outcome categories.
There is also the unconstrained (the most flexible but least parsimonious case, i.e., the generalized ordered logit model gologit1), where the parallel lines assumption is relaxed so that coefficients, $\beta s$ are allowed to vary across $m$ outcome categories [21].

Summary of the location of the partial proportional odds models with respect to parsimony in the number of parameters that are estimated and how flexible the parallel lines assumption can be handled is presented in table 2. From the table it can be seen that the partial proportional odd (PPO) model gives off between the parameter parsimony and the flexibility features of the assumption.

Table 2. Location of the partial proportional odds model

\begin{tabular}{llll}
\hline & OLM (ologit) & PPOM (gologit2) & GOLM (gologit1) \\
\hline Parsimony in parameters & High & Medium & Low \\
Flexibility in assumption & Low & Medium & High \\
\hline
\end{tabular}

OLM: Ordered logit model: PPOM: Partial proportional odds model: GOLM: Generalized ordered logit model (Source: adopted from [22]).

The cumulative probabilities of the standard ordered logit model which is the extreme of the three can be expressed as:

$$
P(Y \leq m \mid X)=F\left(\tau_{m}-X \beta\right), \text { for } m=1,2
$$

On the other hand, the generalized ordered logit model which is fitted with gologit1 has cumulative probabilities as follows:

$$
P(Y \leq m \mid X)=F\left(\alpha_{m}-X \beta_{m}\right), \text { for } \mathrm{m}=1,2, \ldots \ldots \ldots \mathrm{J}
$$

The generalized model (gologit1) differs from the standard ordered logit model in that it has different set of coefficients, $\beta m$ for each outcome category whilst the coefficients of the standard logit model often have the same values across the $m$ categories. Both models have the $\tau$ and $\alpha$ terms as their threshold values or cut-points.

In the case of the partial proportional odds model (gologit2), it is allowed for some of the $\beta$ coefficients in the $\mathrm{m}$ outcomes to be the same whilst some other coefficients $(\beta m)$ can vary across the categories. The partial proportional odds model can therefore be expressed as follows;

$$
P(Y \leq m \mid X)=F\left(\alpha_{m}-X_{1} \beta_{1}+X_{2} \beta_{2}+X_{3} \beta_{m}\right) \text {, for } \mathrm{m}=1,2, \ldots,
$$

When the partial proportional odds model is fitted with gologit 2 command, the constraints are often imposed on the independent variables that violate the parallel line assumption [19]. In this study, this assumption could be violated because of the different mind-set farmers may have on the financial sector, which could hamper their confidence in the sector. The previous experience a farmer may have encountered in dealing with a financial institution can affect his attitude towards the financial institution and this may affect how s/he may express confidence in the financial sector thereby affecting their unobserved feeling of the sector. Different experiences and feelings can translate into shifting the cut-points along the arbitrary continuous scale of the latent $Y^{*}$ variable, the unobserved feeling of farmers in the financial sector which subsequently causes violation of the parallel lines assumption [22].

\section{Results and Discussion}

\subsection{Descriptive Statistics of Variables Included in the Models}

The descriptive statistics of the variables used in this study is presented in table 3. Based on the literature and intuition, these selected variables were hypothesized to have effect on the confidence level of the farmers in the financial institutions of the municipality. An average farm income of GHC. 493.299 was recorded among the farmers with an income range of GHC. 45.00 to GHC. 7000 and an income deviation of GHC. 719.46. Some farmers did not have any education though a mean of almost 9 years of education was observed among the farmers. This implies that an average farmer has obtained basic education. The average months of stay as committed customer to their banks was about 15 months, which implies that on average, a farmer has been with a bank or financial institution for more than a year. Some farmers did not access any loan from any financial institution although the maximum loan amount accessed was GHC. 100,000.00 with a mean loan amount of GHC 1832.99 and some farmers deviating from the mean with a loan amount of GHC 7680.61

Table 3. Descriptive Statistic of Variables included in the Models

\begin{tabular}{lllll}
\hline Variables & Number & Minimum & Maximum & Mean \\
\hline Farm income of respondents & 274 & 45 & 7000 & 493.30 \\
Years of Education & 274 & 0 & 19 & 719.46 \\
Duration as committed customer & 274 & 1 & 144 & 5.95 \\
\hline
\end{tabular}




\begin{tabular}{|c|c|c|c|c|c|}
\hline Variables & Number & Minimum & Maximum & Mean & Std. Dev \\
\hline Amount of Loan obtain & 274 & 0.00 & 100000 & 1832.99 & 7680.61 \\
\hline Sex & 274 & 0 & 1 & 0.675 & 0.46916 \\
\hline Loss of Investment & 274 & 0 & 1 & 0.325 & 0.46916 \\
\hline Access to loan & 274 & 0 & 1 & 0.402 & 0.49109 \\
\hline Investment status & 274 & 0 & 1 & 0.266 & 0.44290 \\
\hline Transactional challenges & 274 & 0 & 1 & 0.35 & 0.47796 \\
\hline
\end{tabular}

\begin{tabular}{llll}
\hline Categorical Variable & & & \\
\hline & Label & Frequency & Percentage \\
\hline & Very confident $=1$ & 43 & 15.7 \\
\multirow{4}{*}{ Level of confidence in financial institutions } & Confident $=2$ & 48 & 17.5 \\
& Somehow confident $=3$ & 60 & 21.9 \\
& No confidence $=4$ & 123 & 44.9 \\
\hline
\end{tabular}

Source: Field Survey, 2019.

Table 3, also presents the categorical variables captured in the study. The confidence level of farmers was measured as a ranked ordered variable (Very confident $=1$; Confident $=2$; Somehow confident $=3$; No confidence $=4$ ) and most of the farmers $(44.9 \%)$ expressed no confidence in the financial institutions, $21.9 \%$ were somehow confident in the financial institutions, $17.5 \%$ were confident whilst $15.7 \%$ indicated that they were very confident in the financial institutions. The high level of lack of confidence has been reported by Mosch and Prast [15]. The study constituted $67.5 \%$ male farmers and $32.5 \%$ of female population, which reflects the low level of participation of women in farming probably due to land ownership and capital constraints. It was of interest to find out if a farmer has ever lost his savings and/or investment in any financial institution before. About $67.5 \%$ of the farmers reported not losing any savings or investment through a financial institution although $32.5 \%$ did indicate that indeed, they have experienced such losses in the past. In terms of loan access, $59.9 \%$ did not access loan whilst $40.1 \%$ reported accessing a loan for farming in the past farming season. The wide response of limited loans access was tied to collateral requirements and high interest couple with the instability of the financial environment. The current investment or savings status can influence or explain their confidence level of the financial sector. It was observed that majority $(73.4 \%)$ of the farmers were not having any investment or savings with any financial institution whilst only $26.6 \%$ of the farmers were having savings or investment at the time of the interview. About $35 \%$ of the farmers reported ever having some challenges with their banks during some transactions whilst majority $(65 \%)$ of the farmers have never had such challenges in the financial sector.

\subsection{Brant Test for Parallel Regression Assumption}

When fitting an ordinal dependent variable, the ordinal logistic (ologit) model is widely used. The model assumes a parallel line or equal coefficient values across the various categories of the ordered dependent variable. However, in most cases this assumption is often violated especially when dealing with large amount of data in a study [19]. When a formal test proves that indeed, there is a violation of the parallel line assumption, the Partial Proportional odd (PPO) model is often adopted to fit the ordinal dependent variable [19]. One of such formal tests among others include the Brant test which jointly test all the variables to see whether all the variables together violate the assumption and also test for each variable on the assumption [19]. This test was therefore conducted to verify if the variables selected for this study actually obeyed or violated the proportional odds assumption. The test results is presented in table 4 .

Table 4. Brant test for parallel regression assumption; estimated coefficients from j-1 binary regressions

\begin{tabular}{llll}
\hline Variables & $\mathbf{y}>\mathbf{1}$ & $\mathbf{y}>\mathbf{2}$ & $\mathbf{y}>\mathbf{3}$ \\
\hline Sex & 1.5980136 & 1.1580241 & 0.86035844 \\
Education in years & 0.09143095 & -0.02942318 & -0.07592949 \\
Farm Income & $7.974 \mathrm{e}-06$ & 0.00001012 & -0.00026918 \\
Duration of bank customer & -0.02768401 & -0.02378827 & -0.01823964 \\
Accessed Loans & 0.1256215 & 0.44528592 & 0.36630245 \\
Loan Amount & 0.00006313 & 0.0000387 & 0.00002374 \\
EnChallenge & -0.35063661 & -1.2100011 & -0.60791978 \\
LosInvestment & 0.11346228 & -0.15097282 & -0.12257064 \\
CINStatus & 2.172294 & 0.6518801 & 0.70254525 \\
Constant & -3.9595399 & -0.23755323 & 0.97528515 \\
\hline
\end{tabular}

$\mathrm{Chi} 2=56.68 \mathrm{P}>\mathrm{chi} 2=0.000 \mathrm{Df}=18 ; \mathrm{N}: \mathrm{B}$ : A significant test statistic provides evidence that the parallel regression assumption has been violated (Source: Field Survey, 2019) 
As seen in table 4, the results indicate that the model violated the assumption of the parallel lines. The significance of the statistic of the joint test $(\mathrm{Chi} 2=56.68 ; \mathrm{P}>\mathrm{chi} 2=$ 0.000 ) indicates that all the variables together violated the proportional odds assumption. The Brant test provides that a significant test statistic is an indication of violation of the assumption. From the results, if the parallel lines assumption was not violated, all the coefficients (except the intercepts) would be the same across all the equations but instead, the coefficients of all the variables differ across the ranks. This clearly indicates that using ologit will provide bias, incorrect, incomplete, or misleading results as posited by Williams [19] due to the gross violation of the parallel lines assumption.

A further test to determine which variables are violating the assumption was conducted using gologit2 autofit command. Reference to table 5 reveals that at the 0.05 level of significance, farm income, access to loans and encounter challenges, all had insignificant p-values indicating that they did not violate the parallel line assumption. This means that constraints were imposed on only these three variables and therefore their coefficients did not appear in the second and third panels. Although if the parallel lines assumption is violated, the model could still be used as indicated earlier. However, it may provide incorrect, incomplete, or misleading results [19]. The result of the test of the individual variables in relation to the violation or otherwise, of the parallel lines assumption is presented in table 5 .

Table 5. Test of parallel-lines assumption of individual variables using the .05 level of significance

\begin{tabular}{ll}
\hline Variables & P-value \\
\hline Sex & 0.00784 \\
Education in years & 0.000 \\
Farm Income & 0.4049 \\
Duration of bank customer & 0.00085 \\
Accessed Loans & 0.9625 \\
Loan Amount & 0.00267 \\
Ever encounter a challenge in the bank & 0.1541 \\
Ever lost any investment & 0.00192 \\
Current investment status & 0.00002 \\
\hline
\end{tabular}

An insignificant p-value provides evidence that those variables did not violate the parallel regression assumption and therefore, constraints were imposed on those variables. (Source: Field Survey, 2019).

If the standard ordered logit model was fitted, there would have been 9 estimated coefficients with assumption of same coefficients across the ranks (equation 1). If the generalized ordered logit model (gologit1; which does not impose constraints) were estimated, there would be $9 \times 3=$ 27 different set of estimated coefficients for each $\mathrm{J}-1$ equation $[23 ; 24]$. Another option is to use non-ordinal alternative such as multinomial logistic regression that does not regard the ranks but assumes multinomial dependent variable. The two test indicated a violation of the parallel line assumption, which therefore justifies the adoption of the partial proportional odd (PPO) model for this paper.

\subsection{Results of the Partial Proportional Odds Model}

Like the F-ratio and Chi-square ratio, the Wald chi-square test is the test of overall goodness of fit of the proportional odds (PPO) model. It tests for the joint explanatory power of the selected independent variables, which in the null hypothesis are assumed to lack any significant impact on the dependent variable. In this model the Wald chi-square test is 69.94, significant at $1 \%$ level of significance and therefore indicates that the null hypothesis is rejected and indeed, at least one of the coefficients of the explanatory variables has an effect on the farmers' level of confidence in the financial sector.

The dependent variable, (confidence level) was ranked and this resulted into the estimation of three models. The gologit2 fitting of the PPO model provided three panels. The very confident category occupies panel one and this is contrasted with the confident, somehow confident and no confidence groups (base category). The signs on the coefficients provide an indication of how likely or otherwise a farmer is to be very confident in the financial institutions of the municipality. As asserted by Williams [19], the results of the PPO model is interpreted by contrasting the current category with the least coded as the base groups. This implies that the $\mathrm{m}^{\text {th }}$ panel results are equivalent to the results of a binary logistic model where categories 1 to $\mathrm{m}$ are coded zero or base outcome and $\mathrm{m}+1$ to $\mathrm{j}$ are often coded as 1 . With regards to this coding, a positive coefficient or odds ratio that exceeds 1 provide an indication that higher values of an explanatory variable increases the likelihood of a farmer having high or being very confident in the financial sector of the municipality and for that matter, the country. A negative coefficient or odds ratio less than 1 however provides that higher values of the explanatory variables increase the odds of being in the current or a lower category of the rank [16]. Table 6 presents coefficients and relative risk ratios of the independent variables on the dependent variable. 
Table 6. Partial Proportional Odds Model of Farmers' Confidence Level in Financial Institutions

\begin{tabular}{|c|c|c|c|c|c|c|c|c|c|}
\hline $\begin{array}{l}\text { Levels of } \\
\text { Confidence }\end{array}$ & Coefficients & RRR & $\mathbf{P}>|\mathbf{z}|$ & Coefficients & RRR & $\mathbf{P}>|\mathbf{z}|$ & Coefficients & RRR & $\mathbf{P}>|\mathbf{z}|$ \\
\hline \multicolumn{4}{|l|}{ Very Confidence } & \multicolumn{3}{|l|}{ Confidence } & \multicolumn{3}{|c|}{ Somehow Confidence } \\
\hline Sex & $\begin{array}{l}3.0355 * * * \\
(0.7456)\end{array}$ & $\begin{array}{l}29.8214 \\
(23.7968)\end{array}$ & 0.000 & $\begin{array}{l}0.7931 * * \\
(0.3736)\end{array}$ & $\begin{array}{l}2.0829 \\
(0.7814)\end{array}$ & 0.034 & $\begin{array}{l}0.7369 * * \\
(0.2947)\end{array}$ & $\begin{array}{l}2.0353 \\
(0.6028\end{array}$ & 0.012 \\
\hline Education in years & $\begin{array}{l}0.3978^{* * *} \\
(0.0922)\end{array}$ & $\begin{array}{l}1.4698 \\
(0.1412)\end{array}$ & 0.000 & $\begin{array}{l}-0.0620^{*} \\
(0.0333)\end{array}$ & $\begin{array}{l}0.9363 \\
(0.0352)\end{array}$ & 0.063 & $\begin{array}{l}-0.1236^{* * *} \\
(0.0314)\end{array}$ & $\begin{array}{l}0.8815 \\
(0.0288)\end{array}$ & 0.000 \\
\hline Farm Income & $\begin{array}{l}-0.0001 \\
(0.0002)\end{array}$ & $\begin{array}{l}1.0005 \\
(0.0006)\end{array}$ & 0.532 & & & & & & \\
\hline $\begin{array}{l}\text { Duration of bank } \\
\text { customer }\end{array}$ & $\begin{array}{l}-0.0610 * * * \\
(0.0129)\end{array}$ & $\begin{array}{l}0.9399 \\
(0.0128)\end{array}$ & 0.000 & $\begin{array}{l}-0.0151 * * \\
(0.0063)\end{array}$ & $\begin{array}{l}0.9850 \\
(0.0064)\end{array}$ & 0.017 & $\begin{array}{l}-0.0150 * \\
(0.0068)\end{array}$ & $\begin{array}{l}0.9842 \\
(0.0073\end{array}$ & 0.028 \\
\hline Accessed Loans & $\begin{array}{l}0.4731 \\
(0.3157)\end{array}$ & $\begin{array}{l}1.5829 \\
(1.3053)\end{array}$ & 0.134 & & & & & & \\
\hline Loan Amount & $\begin{array}{l}0.0002 * * * \\
(0.00006)\end{array}$ & $\begin{array}{l}1.0002 \\
(0.00007)\end{array}$ & 0.000 & $\begin{array}{l}0.00002 \\
(0.00002)\end{array}$ & $\begin{array}{l}1.0000 \\
(0.00002)\end{array}$ & 0.327 & $\begin{array}{l}0.00002 \\
(0.00002)\end{array}$ & $\begin{array}{l}1.0000 \\
(0.00002)\end{array}$ & 0.471 \\
\hline EnChallenge & $\begin{array}{l}-0.8484 * * * \\
(0.3138)\end{array}$ & $\begin{array}{l}0.2314 \\
(0.1897)\end{array}$ & 0.007 & & & & & & \\
\hline LosInvestment & $\begin{array}{l}1.8545^{* * *} \\
(0.6583)\end{array}$ & $\begin{array}{l}6.6466 \\
(4.5472)\end{array}$ & 0.005 & $\begin{array}{l}-0.4577 \\
(0.3652)\end{array}$ & $\begin{array}{l}0.6678 \\
(0.2524)\end{array}$ & 0.210 & $\begin{array}{l}-0.2204 \\
(0.3585)\end{array}$ & $\begin{array}{l}0.6788 \\
(0.2579)\end{array}$ & 0.539 \\
\hline CINStatus & $\begin{array}{l}6.3584 * * * \\
(1.2909)\end{array}$ & $\begin{array}{l}753.8562 \\
(931.9624)\end{array}$ & 0.000 & $\begin{array}{l}0.3211 \\
(0.3917\end{array}$ & $\begin{array}{l}1.5722 \\
(0.6683)\end{array}$ & 0.412 & $\begin{array}{l}0.6777^{*} \\
(0.3733)\end{array}$ & $\begin{array}{l}1.9079 \\
(0.7329\end{array}$ & 0.069 \\
\hline Constant & $\begin{array}{l}-17.0940^{* * *} \\
(3.6527) \\
\end{array}$ & $\begin{array}{l}2.96 \mathrm{e}-08 \\
(1.10 \mathrm{e}-07) \\
\end{array}$ & 0.000 & $\begin{array}{l}1.5585 \\
(1.1302) \\
\end{array}$ & $\begin{array}{l}6.6164 \\
(7.7597) \\
\end{array}$ & 0.168 & $\begin{array}{l}0.0478 \\
(0.9464) \\
\end{array}$ & $\begin{array}{l}0.9830 \\
(0.9498 \\
\end{array}$ & 0.960 \\
\hline
\end{tabular}

Significant at $* 10 \%, * 5 \%, * * * 1 \%$ level. CINStatus $=$ Current Investment Status, LosInvestment $=$ Lost Investment or Savings, EnChallenge $=$ Encounter a challenge before $\mathrm{RRR}=$ Relative Risk Ratio. Wald chi2 $(21)=69.94$, Prob $>$ chi2 $=0.0000$ and Pseudo $\mathrm{R}^{2}=0.2224$; N:B values in parenthesis are standard errors. (Source: Field Survey, 2019).

From table 6 , sex was found to be positive at $1 \%$ level of significance with a relative risk ratio (RRR) of about 29.8 as seen in the first panel. This means that all things being equal, male farmers are about 29.8 times more likely to be very confident in the financial institutions than female farmers. This is probably due to the emotional weakness of women and the possibility that men generally save or invest more couple with their higher loan accessibility than females. Lower level of female confidence in banking is consistent with the results of the Dutch Banking Association [13] but contradicts Mosch and Prast [25]. Farmers' number of years in formal education is positive and significant at $1 \%$ and implies that holding other factors constant, an additional year of education increases the probability of farmers being very confident in the financial sector by 1.47 times rather than being confident, somehow confident and not confident. This may imply that the more educated a farmer is, the better his/her knowledge on the principles of investment and savings in these banks. Positive relationship between education and higher level of confidence has been reported in Bola [11]. Educated people may engage the banks with negotiations for better services. On the contrary, the results reveals that the coefficient of duration a farmer have been with his/her financial institution, all things being equal, reduces farmers' likelihood of being very confident in the financial institutions by about 0.94 times. This may be explained as the continuous bad experiences they may be going through with customer service providers of these banks and probably lost of money through their operations.

The results also indicates that an increase in the amount of money farmers receive as loan from a financial institution increases their likelihood of being very confident as against confident, somehow confident and no confidence by 1.00 times ceteris paribus. Consistent with prior expectation, farmers who constantly experience challenges with their financial institutions are about 0.23 times less likely to be very confident in the financial institution holding all other variables constant. This is obvious because constant challenges with banks are likely to create problem of mistrust among customers because of lack of satisfaction as reported in Bola [11]. Contrary to prior expectation, farmers who have ever lost their savings or investment are still about 6.65 times more likely to be confident in the financial institutions than those who have not loss any investment ceteris paribus. This is probably due to government interventions that have helped them retrieve their principals in the past. The timely interventions by the regulator might have boosted farmers' confidence in the financial sector. Famers who are currently having savings or investment with these banks were about 753.86 times more likely to be very confident in the financial institutions rather than being confident, somehow confident and not confident, ceteris paribus. This met our prior expectation because once the farmers have trust in the financial institutions and continue to save or invest with these financial institutions, they are more likely to be very confident in them. It however disagrees with Drobot [16] who reported a negative relationship between household savings and their confidence in the banks.

In the second panel (table 6), some of the variables that violated the parallel lines assumptions have different coefficients and RRR across the panels. The other variables that met the parallel lines assumption (farm income, acess to loans and encounter challenge), had the same coefficients and did not appear in the second and third panels. Again, holding 
other factors constant, male farmers were found to be about 2.08 times more likely to be confident in the financial sector rather than being somehow confident or not having confidence. Increase in the number of years of formal education by one year reduces the likelihood of a farmer being confident by 0.94 times ceteris paribus. Duration in months a farmer have being in a bank reduces the likelihood of the farmer to be confident by 0.99 times than being somehow confident or having no confidence, ceteris paribus.

In the third panel, male farmers are still about 2.04 times more likely to be somehow confident in the financial sector rather than having no confidence in the sector holding other factors constants. An increase in years of education of a farmer decreases his/her likelihood of being somehow confident in the financial sector by 0.88 times all things been equal. Increase in the duration a farmer have in a bank by a month reduces the probability of him/her being somehow confident by 0.98 times. Finally, farmers who were currently saving or investing in a bank were about 1.91 times more likely to be somehow confident rather than not having confidence at all, ceteris paribus.

\subsection{Model Diagnosis Tests}

Most of the literature available points to the fact that in most instances, ordinal models are fitted with the ologit or mlogit fitting commands that does not consider the possibility of violation of the parallel line assumptions. The use of a partial proportional odds model (PPO) in this paper to examine the level of confidence farmers have on the financial institution is a major breakthrough as most related studies often use ordinal regression models without regards for the requirement of meeting the parallel line assumptions [22]. In order to prove the worth of the model in properly fitting the data, model diagnosis test was performed using the Akaike's Information Criterion (AIC). With reference to table 7, we obtained an ordered logit (ologit) AIC value of 665.7131, multinomial logit (mlogoit) model (AIC = 654.9003), generalized ordered logit (gologit1) model produced an AIC value of 602.7878 and a partial proportional odds (PPO) (gologit2) model had the least AIC of 596.8139. The principle of the use of AIC as a measure requires that the best fitted model is the one with the least AIC value. Therefore, using Akaike's Information Criterion (AIC) as a measure, further provided the statistical evidence to choose the partial proportional odds (PPO) model since it provided the smallest AIC indicating a best-fitted model for this study [22]. The AIC result of the models is presented in table 7 .

Table 7. Comparison of Goodness of fit using Akaike's information criterion

\begin{tabular}{llll}
\hline Model & Observations & Degree of freedom & Akaike's Information Criterion (AIC) \\
\hline Ologit & 274 & 12 & 665.7131 \\
Mlogit & 274 & 30 & 654.9003 \\
Gologit & 274 & 30 & 602.7878 \\
gologit2 & 274 & 24 & 596.8139 \\
\hline
\end{tabular}

(Source: Field Survey, 2019).

\section{Conclusion and Policy Recommendation}

This study sought to examine the confidence level of farmers in the financial sector of the country; a case of the Ejura Sekeredumase Municipality of the Ashanti Region. The study used the PPO model to assess the determinants that affect the level of confidence this farmers repose on the financial sector. In all 274 randomly selected farmers were taken through a properly designed phone coded questionnaires. About $44.9 \%$ reported not having confidence in the financial institutions of the country, about $21.9 \%$ were somehow confident in the sector, $17.5 \%$ were confident whereas only $15.7 \%$ were very confident in the sector. Male farmers were more likely to be very confident in the financial sector whilst education, those who ever lost savings or investment as well as those with current savings and/or investment all had positive outcome in the likelihood of being very confident. Duration of farmers in a financial institution and farmers who ever encounter challenges in a financial institution were having negative likelihood to be very confident in the financial institutions of the country.

Financial institutions are recommended to strengthen their relationships with customers through improve customer services, especially with those that have been with them for a longer period of time. This will increase their confidence and trust in the financial institution.

The Central Bank should develop a different proactive educational models or approaches to educate farmers on how to identify risk and other exposures that may be associated with the financial institutions operating in the rural areas in order to enable them to take decisions towards savings and investment. This will boost their confidence levels.

Banks should embark on campaigns to encourage savings and investment among farmers in order to increase their confidence level in the banks and cushion them for credit facilities to boost their production.

Banks should make their loan accessibility requirements flexible so that as many farmers as possible can obtain loans for production in order to strengthen their confidence. 


\section{References}

[1] Enu Patrick (2014), Analysis of the Agricultural Sector of Ghana and its Economic Impact on Economic growth, Academic Research International 5 (4). ISSN: 2223-9944, eISSN: 2223-9553.

[2] Ghana Statistical Service [GSS](2019). Rebased 2013-2018 Annual Gross Domestic Product, April 2019 Edition www.statsghana.gov.gh. Accessed on $20^{\text {th }}$ January, 2020.

[3] Awoyemi, A. E.; Olajide, O. A. Assessment of the Degree of Households' Vulnerability to Climate Variability in Nigeria BT - Handbook of Climate Change Resilience; Leal Filho, W., Ed.; Springer International Publishing: Cham, Switzerland, 2018; pp. 1-16, ISBN 978-3-319-71025-9.

[4] Abunyuwah, I., Yenibehit, N., \& Ahiale, E. D. (2019). Technical Efficiency of Carrot Production in the Asante-Mampong Municipality Using Stochastic Frontier Analysis. Journal of Agriculture and Environmental Sciences, 8 (2), 14-21.

[5] Echeverría, R. G., \& Beintema, N. M. (2009). Mobilizing financial resources for agricultural research in developing countries: Trends and mechanisms. Global Forum on Agricultural Research.

[6] Akuffo-Duah, B. (2011). Competition in the Banking Industry of Ghana (Dissertation; Commonwealth Executive Masters in Business Administration (CEMBA), Kwame Nkrumah University of Science and Technology).

[7] BANK OF GHANA (2019): Banking Sector Report. https://www.bog.gov.gh/banking_sect_report/banking-sectorreport-september-2019/. Accessed on $10^{\text {th }}$ January 2020.

[8] Oduro, R., Asiedu, M. A., \& Gadzo, S. G. (2019). Impact of credit risk on corporate financial performance: Evidence from listed banks on the Ghana stock exchange. Journal of Economics and International Finance, 11 (1), 1-14.

[9] Sarpong S. (2018) Ensuring Sanity in Ghana's Financial Sector: A Focus on Ghana's Microfinance Institutions. In: Díaz Díaz B., Idowu S., Molyneux P. (eds) Corporate Governance in Banking and Investor Protection. CSR, Sustainability, Ethics \& Governance. Springer, Cham, pp. 287-301. https://doi.org/10.1007/978-3-319-70007-6_14. Accessed on 9th June, 2019.

[10] Ayanou T. (2011). An Impact Assessment of Microfinance Institutions on Women Entrepreneurs in Small and Medium Enterprises A Case Study of Sinapi Aba Trust. Kwame Nkrumah University of Science and Technology.

[11] Bola, M. (2017). Public confidence in microfinance institutions and demand for microfinance services in Ghana (Undergraduate dissertation, Ashesi University College).

[12] Skvarciany, V., \& Jureviciene, D. (2013). The Concept of Confidence in Bank. In T. Loster, \& T. Pavelka (Eds.), 7th International Days of Statistics and Economics (pp. 532-540). Melandrium.

[13] Dutch Banking Association [DBA], (2017). Banking Confidence Monitor 2017. Gustav Mahlerplein, Amsterdam. Retrieved from https://www.nvb.nl/media/1103/banking confidence-monitor-2017.pdf on 9th June, 2019.

[14] Hussein, K. (2016). Bank-Level Stability Factors and Consumer Confidence-A Comparative Study of Islamic and Conventional Banks' Product Mix. In Islamic Finance (pp. 86-104). Palgrave Macmillan, Cham.

[15] Mosch, Robert; Prast, Henriëtte (2010): Confidence and trust: empirical investigations for the Netherlands and the financial sector, Beiträge zur Jahrestagung desVereins für Socialpolitik 2010: Ökonomie der Familie - Session: Trusting Banks in a Financial Crisis, No. A1-V2, Verein für Socialpolitik, Frankfurt a. M. Retrieved from http://hdl.handle.net/10419/37384. Accessed on $9^{\text {th }}$ June, 2019

[16] Drobot, S. (2015). Consumer Confidence and Household Deposits (Doctoral dissertation, Kyiv School of Economics).

[17] Ministry of food and agriculture (2012). Ejura Sekeredumase municipal assembly. Retrieved from http://www.MoFA.gov.gh. Accessed on 9th June, 2019.

[18] Ghana Statistical Services,. (2010). Population \& Housing Census: Summary Report of Final Results (p. 23). Accra: Ghana Statistical Services. Retrieved from http://www.statsghana.gov.gh/docfiles/2010phc/Census2010 Summary_report_of_final_results.pdf

[19] Williams, R. (2006). Generalized ordered logit/partial proportional odds models for ordinal dependent variables. The Stata Journal, 6 (1), 58-82.

[20] Bender, R. and Grouven, U. (1998). Using binary logistic regression models for ordinal data with non-proportional odds. Journal of Clinical Epidemiology, 51 (10), 809-816.

[21] Long, J. S., and J. Freese. 2006. Regression Models for Categorical Dependent Variables Using Stata. 2nd ed. College Station, TX: Stata Press.

[22] Soon, J. J. (2010). The determinants of students' return intentions: A partial proportional odds model. Journal of Choice Modelling, 3 (2), 89-112. 